\title{
Prevalence of Reported Migraine Headaches in Canadian Adolescents
}

\author{
K.E. Gordon, J.M. Dooley, E.P. Wood
}

\begin{abstract}
Objective: To examine self-reported prevalence data for migraine among adolescent Canadians and to explore how reported migraine treatment varies by age. Methods: We analyzed the microdata files of the Canadian National Population Health Survey (1996-1997). Respondents reported whether they had "migraine headaches diagnosed by a health professional". They also reported whether they received "any treatment or medication for migraine headaches", with treatments subdivided into drug, diet or "other". Results: $99.9 \%$ of 173,216 eligible respondents reported whether they had migraine headaches. Migraine was reported by $2.4 \%$ of Canadian youth aged 12-14 years and by $5.0 \%$ of $15-19$ year-olds compared to $7.2 \%$ of adults aged $\geq 20$ years of age $(\mathrm{p}<0.0001$, chi-square). Active treatment was used by $51.0 \%$ - higher by females $(53.1 \%)$ than males $(44.7 \%)(\mathrm{p}<0.0001$ chi-square). Treatment was used by $45.1 \%$ of $12-14$ year-olds, by $45.7 \%$ of $15-19$ year-olds and by $51.5 \%$ of those $\geq 20$ years $(\mathrm{p}=0.0027)$. The nature of the active treatment choice (drug, diet or other) did not significantly vary within the age groups studied. Conclusions: We present robust estimates of self-report diagnosed migraine prevalence, derived from a large nationally representative population survey. Estimates of the prevalence of active treatment for migraine provide insight into the burden of migraine within this population.
\end{abstract}

RÉSUMÉ: Prévalence de la céphalée migraineuse rapportée par les adolescents canadiens. Objectif: Examiner les données sur la prévalence de la migraine rapportée par les adolescents canadiens et explorer comment le traitement de la migraine qu'ils rapportent varie selon l'âge. Méthodes: Nous avons analysé les données de l'Enquête nationale sur la santé de la population canadienne (1996-1997). Les répondants ont rapporté s'ils avaient des "migraines dont le diagnostic avait été posé par un professionnel de la santé". Ils ont également rapporté s'ils recevaient "tout traitement ou médication pour la migraine", les traitements étant divisés en médicaments, diète ou "autre". Résultats: $99,9 \%$ des 173216 répondants éligibles ont répondu à ces questions. 2,4\% des jeunes canadiens âgés de 12 à 14 ans et 5,0\% des 15 à 19 ans comparés à 7,2\% des adultes âgés de $\geq 20$ ans $\left(\chi^{2} \mathrm{p}<0,0001\right)$. 51,0\% utilisait un traitement actif, soit plus de filles (53,1\%) que de garçons (44,7\%; $\left.\chi^{2} \mathrm{p}<0,0001\right) .45,1 \%$ des 12 à 14 ans, 45,7\% des 15 à 19 ans et $51,5 \%$ des 20 ans et plus $(\mathrm{p}=0,0027)$ utilisaient un traitement. Le choix de la nature du traitement actif (médicament, diète ou autre) ne variait pas de façon significative entre les groupes d'âge étudiés.

Can. J. Neurol. Sci. 2004; 31: 324-327

Migraine is ubiquitous, affecting individuals of all ages, from infancy to old age. ${ }^{1}$ Ascertaining the prevalence of migraine in childhood has been complicated by disputes regarding the definition of childhood migraine and by apparent population differences.

We studied the data from the Canadian National Health Population Survey, which surveys a nationally representative sample of Canadians. A diagnosis of migraine was accepted if it had been made by a health professional.

This large nationally representative cohort provides insights into the prevalence of migraine in Canadian adolescents compared to adults and provides data on self-reported preferred methods of headache management.

\section{Methods}

Our analysis was based on the public use microdata set of the second cycle of the National Population Health Survey, conducted by Statistics Canada in 1996-97.2,3 The National Population Health Survey is a Canadian national survey designed to collect information related to the health of the Canadian population. A multistage, stratified sampling design was used to obtain a representative sample of household residents in all 10 provinces, exclusive of: Indian reserves, Canadian military bases and some remote areas in Quebec and Ontario. ${ }^{4}$ The survey comprised questions about health status, heath determinants, and health care utilization. Within this survey, each subject 12 years of age or older was asked "Do you

From the Division of Pediatric Neurology, Department of Pediatrics, Dalhousie University, and IWK Health Centre, Halifax, Nova Scotia, Canada. ReCEIVED SEPTEMBER 10, 2003. ACCEPTEDin FINALFORM MARCH 2, 2004 Reprint requests to: K.E. Gordon, Department of Pediatrics, IWK Health Centre, 5850 University Avenue, Halifax, Nova Scotia, Canada B3J 3G9 
have migraine headaches diagnosed by a health professional?". Subjects responding affirmatively to this question were subsequently asked "Do you receive any treatment or medication for migraine headaches?", and the nature of any such treatment or medication (drug, diet or "other").

We calculated the prevalence of migraine headache and its treatment, focusing on the adolescent age groups (12-14 years and 15-19 years) and gender. The data were analyzed using Systat v9.0. ${ }^{5}$ Weights were recoded to reflect the sample size. Where appropriate, prevalence estimates are accompanied by 95\% confidence intervals (CI), based on sample size weights. Chi-square technique was used for all bivariate analyses and odds ratios as a measure of association. All analyses were performed within the parameters outlined for analysis of Statistics Canada microdata files.

\section{RESUlts}

Responses to the question "do you have migraine headaches diagnosed by a health professional?" were received from 173,012 of 173,216 eligible participants (99.9\%). As this question was not posed to those less than 12 years of age, the cohort is representative of $24,567,700$ Canadians over 12 years of age in 1996-1997.

Among the respondents, 12,442 reported that they suffered from migraine headaches diagnosed by a health professional, representing 1,670,600 Canadians or $6.8 \%$ of the population (95\% CI: $6.7 \%, 6.9 \%)$. Migraine headaches were reported by $3.5 \%$ of males (95\% CI: $3.3 \%, 3.6 \%)$ compared to $10.1 \%$ of females (95\% CI: 9.8\%, 10.3\%) ( $\mathrm{p}<0.0001$, chi-square).

The prevalence of migraine increased with age and was reported by $2.4 \%$ of adolescents aged $12-14$ years $(95 \% \mathrm{CI}$ : $2.0 \%, 2.7 \%$ ), and by $5.0 \%$ of the $15-19$-year-olds (95\% CI: $4.6 \%, 5.4 \%$ ) compared to $7.2 \%$ of adults, aged 20 years or older (95\% CI: $7.1 \%, 7.4 \%),(\mathrm{p}<0.0001$, chi-square). Males were uniformly less likely to report migraine at all ages (Table).

Among those reporting migraine, 51.0\% reported using some form of treatment $(95 \% \mathrm{CI}: 50.0 \%, 52.0 \%)$. Females were more likely to treat $(53.1 \%, 95 \%$ CI: $51.9 \%, 54.3 \%)$ than males (44.7\%, 95\% CI: 42.6\%, 46.8\%) ( $<<0.0001$, chi-square). Treatment was also related to age and was employed by $45.1 \%$ of 12-14-year-olds (95\% CI: $36.9 \%, 53.2 \%$ ), by $45.7 \%$ of $15-19$ year-olds (95\% CI: $41.4 \%, 49.8 \%)$ and by $51.5 \%$ of those over 20 years $(95 \%$ CI: $50.4 \%, 52.5 \%)(\mathrm{p}=0.0027)$.

Of those who treated their migraine with drugs, diet or other therapies, the choice of treatment modality did not differ by age. Drug treatment was employed by $95.4 \%$ of those under age 20 years compared to $94.8 \%$ of the older respondents ( $\mathrm{p}=\mathrm{NS})$. Dietary therapy was used by $6.8 \%$ and $6.1 \%$ of the younger and older groups respectively ( $\mathrm{p}=\mathrm{NS}$ ), and other therapies were used by $4.5 \%$ and $6.7 \%$ of each respective group ( $\mathrm{p}=\mathrm{NS}$ ).

Those who used diet to control their headaches were less likely to co-medicate with drugs (OR: $0.25, \mathrm{p}<.0001)$. Similarly $34 \%$ of those who used "other" treatments also used medication (OR: 0.005, P<.0001).

\section{DISCUSSION}

The design of the Canadian National Population Health Survey involves a stratified multistage probability sample of
Table: Response to the question "Do you have migraine headaches diagnosed by a health professional?" Divided by age and sex

\begin{tabular}{lllll}
\hline & Age group & Prevalence & $\mathbf{9 5 \%}$ CI \\
\multirow{4}{*}{ Males } & $12-14$ & 1.8 & 1.4, & 2.3 \\
& $15-19$ & 3.0 & 2.6, & 3.5 \\
& $\geq 20$ & 3.6 & 3.5, & 3.8 \\
& & & & \\
Females & $12-14$ & 2.9 & 2.4, & 3.6 \\
& $15-19$ & 7.1 & 6.4, & 7.7 \\
& $\geq 20$ & 10.7 & 10.5, & 11.0 \\
\hline
\end{tabular}

Canadian households, and is designed to be representative of the national population. As the questions asked in this survey were only posed to those over 12 years of age, the study allows inference about the Canadian population of $24,567,700$ over 12 years of age.

Our estimates of migraine prevalence are similar to those derived from the United States population derived from the 1989 National Health Interview Survey. ${ }^{6}$ Rates of migraine prevalence were similar for males and females aged 6-17 (2.1\% and 2.3\% respectively), with increased prevalence in females $(6.8 \%)$ over males $(2.6 \%)$ in 18-24-year-olds.

Previous studies of migraine in childhood have reported prevalence rates which have ranged from $0.4 \%$ to $27 \% .^{7-18}$ Variability in the diagnostic criteria for migraine can partly explain the wide range of reported prevalence rates. There are no universally accepted diagnostic criteria for migraine as even the International Headache Society (IHS) criteria have been criticized. ${ }^{19,20}$ In our study a diagnosis of migraine was accepted if made by a health professional. Among school-aged children the average prevalence rate for migraine is from $3.8 \%$ to $3.9 \%,{ }^{7,21}$ which is similar to our prevalence rate of $4.0 \%$ for those aged 19 years and younger. Several studies have shown an increase in prevalence as adolescence progresses. ${ }^{7-10}$ Similarly, migraine was twice as prevalent in our older adolescents than in the younger group.

Earlier studies have also shown an increased prevalence of migraine in girls, especially after puberty. In our population, the rates were $65 \%$ higher for girls aged 12-14 years, almost two and a half times higher for the 15-19-year-olds and three times higher among adult women.

Studies to date have represented regional groups of children and may, therefore, have limited applicability to other populations. The studies of Bille ${ }^{7}$ and Sillanpää8,9,11,14-18 have prospectively studied large cohorts of Swedish and Finnish children. Sillanpää, 8,9 however, showed the prevalence of migraine in Swedish-speaking children to be almost twice that of a simultaneously studied unselected group of Finnish-speaking children.

In this study slightly more than half reported treatment with drugs, diet or other therapies. Treatment was more likely employed by females and by those over the age of 20 years. More than $95 \%$ used drugs, although it was not possible to 
identify whether drug use referred to prescription or nonprescription medication. In a previous study of adult Canadians with migraine, $44 \%$ used prescription medications and $91 \%$ had used nonprescription drugs. ${ }^{22}$ The evidence to support the use of most prophylactic therapies for childhood migraine is extremely poor, although common abortive therapies, such as ibuprofen, are effective. ${ }^{23}$

Diet was used by $6.2 \%$ of respondents to treat their migraine in the current study. In a previous study of a regional clinic-based cohort, followed after 10 years, $6.6 \%$ reported that foods precipitated their headaches. ${ }^{24}$ For those who chose other forms of treatment, very few used concomitant drug therapy. This suggests that there is a small population of migraine sufferers who manage their headaches with alternate therapies. Of more importance in this population-based sample approximately half of migraine sufferers, especially younger patients, manage their headaches without any specific form of therapy. Presumably these individuals use such methods as precipitant avoidance and sleep.

As the stratification and clustering involved in the sample's design may only partially be taken into account by the weights in the public use microdata sets, we chose to use sample variance rather than the population variance for our estimates of variability. Our derived estimates are likely to underestimate the true sample variance and overestimate the population variance.

To our knowledge, the question about migraine used in the National Population Health Survey was not validated against an external standard. A similar question "have you ever had migraine" has been validated against a diagnostic telephone interview administered by physicans trained in headache diagnosis, with a sensitivity of $75.8 \%$ (95\% CI: $72.4,79.0)$ and specificity of $86.4 \%$ (95\% CI: 84.3, 88.3). ${ }^{25}$ In an Internet based study of subjects reporting migraine, after reviewing subjects' narrative description of headache qualities, a neurologist assigned a high or moderate probability of migraine to $97 \%$, and to $97 \%$ using IHS criteria. ${ }^{26}$ These studies suggest that the question used in the National Population Health Survey may be valid, at least within adult populations. Despite the availability of the IHS criteria, there is ongoing disagreement about the diagnostic standards for pediatric migraine. ${ }^{19,20}$ When studied, the reliability of pediatric headache diagnosis (inter-observer agreement) ranges from 0.19 to 0.53 (weighted kappa). ${ }^{27} \mathrm{We}$ suspect that the question "do you have migraine headaches diagnosed by a health professional?" provides valid estimates of a basal rate of migraine prevalence.

Large, nationally representative datasets are important to guide health policy. Supplementary analyses of these same datasets have the potential to answer clinically relevant, important questions. One drawback to these supplementary analyses is that relevant and pertinent questions and their answers may (or may not) have been asked of the respondents within the original survey. Access to Statistics Canada health datasets is currently at an unprecedented level through the Data Liberation Initiative. It is our hope that other researchers will explore additional neurological questions within these datasets.

In conclusion, the prevalence of migraine diagnosed by a health professional increased progressively from a low of $1.78 \%$ in boys aged 12-14 years to a high of $10.71 \%$ in adult women. Approximately half used therapy with drugs, diet or other therapies, of whom the vast majority used medications. This study of a large diverse nationally representative cohort provides important information on the prevalence of migraine and preferred methods of managing headaches.

\section{REFERENCES}

1. Vahlquist B, Hackzell G. Migraine of early onset: a study of thirtyone cases in which the disease first appeared between one and four years of age. Acta Paediatr 1949;38:622-636.

2. Statistics Canada. National Population Health Survey (NPHS), 1996: public use microdata "general" file [machine readable data file]. Ottawa, ON. Statistics Canada. 1998.

3. Statistics Canada. National Population Health Survey 1996-97: user's guide for the public use microdata files: household component - 82M0009XPB. Ottawa, ON. Statistics Canada. 1998.

4. Tambay JL, Catlin G. Sample design of the national population health survey. Health Rep 1995;7(1):29-38.

5. SYSTAT. Chicago, IL60611: SPSS Inc., 1998.

6. Stang PE, Osterhaus JT. Impact of migraine in the United States: data from the National Health Interview Survey. Headache 1993; 33:29-35.

7. Bille B. Migraine in school children. A study of the incidence and short term prognosis, and a clinical, psychological and encephalographic comparison between children with migraine and matched controls. Acta Paediatr 1962;51(Suppl 136):1-151.

8. Sillanpää M, Westerén I, Urponen H. [Children with long-term illnesses, disabilities and handicaps in Åboland. Prevalence, social bckground and habilitation services]. Kansanterveytiet Julk M 77, 1984;1-84. (In Finnish with English summary)

9. Sillanpää M, Urponen H. [Children with long-term illnesses, disabilities and handicaps in the Province of Turku and Pori. Prevalence, social background and habilitation services.] Lääkintöhall Tutk 30 1984; 1-127. (In Finnish with English summary)

10. Abu-Arefeh I, Russell G. Prevalence of headache and migraine in schoolchildren. Br Med J 1994;309:765-769.

11. Sillanpää M. Prevalence of migraine and other headache in Finnish children starting school. Headache 1976;5:288-290.

12. Pothmann R, v. Frankenberg SV, Mueller B, Sartory G, Hellmeier W. Epidemiology of headache in children and adolescents: evidence of high prevalence of migraine among girls under 10 . Int J Behav Med 1994;1:76-89.

13. Raieli V, Raimondo D, Cammalleri R, Camarda R. Migraine headache in adolescents: a student population-based study in Monreale. Cephalgia 1995;15:5-12.

14. Sillanpää M. Prevalence of headache in prepuberty. Headache 1983;23:10-14.

15. Sillanpää $M$, Piekkala $P$. Prevalence of migraine and other headaches in early puberty. Scand J Prim Health Care 1984;2:2732.

16. Sillanpää M, Anttila P. Increasing prevalence of headache in 7-yearold school children. Headache 1996;36:466-470.

17. Sillanpää M. Changes in the prevalence of migraine and other headaches during the first seven school years. Headache 1983;23:15-19.

18. Sillanpää M, Piekkala $\mathrm{P}$, Kero P. Prevalence of headache at preschool age in an unselected child population. Cephalgia 1991;11:239-242.

19. Winner P, Martinez W, Mante L, Bello L. Classification of pediatric migraine: proposed revisions to the IHS criteria. Headache 1995;35:407-410.

20. Maytal J, Young M, Schechter A, Lipton RB. Pediatric migraine and the International Headache Society (IHS) criteria. Neurology 1997;48:602-607.

21. Sillanpää M, Peltonen T. Occurrence of headache amongst school children in a Northern Finnish community. In: Sicuteri F (Ed.) Headache: New Vistas. Florence: Biomedical Press 1977; 5-8.

22. Edmeads J, Findlay H, Tugwell P, et al. Impact of migraine and tension-type headache on life-style, consulting behaviour and 
medication use: a Canadian population survey. Can J Neurol Sci 1993;20:131-137.

23. Dooley JM, Gordon KE. Headaches in Childhood. In: Feldman W (Ed). Evidence Based Pediatrics. B.C. Decker 2000.

24. Dooley JM, Bagnell A. The prognosis and treatment of headaches in children - a ten year follow-up. Can J Neurol Sci 1995;22:47-49.

25. Gervil M, Ulrich V, Olesen J, Russell MB. Screening for migraine in the general population: validation of a simple questionnaire. Cephalagia 1998;18:342-348.

26. Lenert LA, Looman T, Agoncillo T, et al. Potential validity of conducting research on headache in internet populations. Headache 2002;42:200-203.

27. Wolstein JR, Seshia SS, Haese P, et al. Inter-observer agreement in the diagnosis of childhood headache. Headache 1994;34:467-470. 